\title{
Mechanistic study of simultaneous arsenic and fluoride removal using granular $\mathrm{TiO}_{2}$-La adsorbent
}

\author{
Li Yan ${ }^{\mathrm{a}, \mathrm{b}}$, Haowei Tu ${ }^{\mathrm{c}}$, Tingshan Chan ${ }^{\mathrm{c}}$, Chuanyong Jing ${ }^{\mathrm{a}, \mathrm{b}, *}$ \\ a State Key Laboratory of Environmental Chemistry and Ecotoxicology, Research Center for Eco-Environmental Sciences, Chinese Academy of Sciences, Beijing 100085, China \\ ${ }^{\mathrm{b}}$ University of Chinese Academy of Sciences, Beijing 100049, China \\ ' National Synchrotron Radiation Research Center, 101 Hsin-Ann Road, Hsinchu Science Park, Hsinchu 30076, Taiwan
}

\section{H I G H L I G H T S}

- Simultaneous As(III) and F removal is achieved by using granular $\mathrm{TiO}_{2}-\mathrm{La}$ composite.

- $\mathrm{LaCO}_{3} \mathrm{OH}$ showing orientated growth on $\mathrm{TiO}_{2}\{100\}$ facet with matched lattice fringes.

- Molecular-level coadsorption mechanism is investigated by EXAFS and DFT calculation.

- The importance of crystal facet in material synthesis and adsorption is highlighted.

\section{A R T I C L E I N F O}

\section{Article history:}

Received 16 September 2016

Received in revised form 28 October 2016

Accepted 31 October 2016

Available online 1 November 2016

\section{Keywords:}

Coexisting As and $\mathrm{F}$

Hybrid $\mathrm{TiO}_{2}$-La adsorbent

Crystal facets

Orientated growth

Molecular-level mechanisms
G R A P H I C A L A B S T R A C T

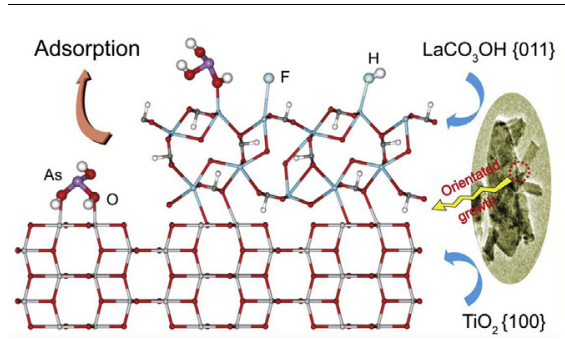


Among various technologies for As and F removal, adsorption is considered suitable because of its high efficiency, costeffectiveness, and feasible operation [6-9]. Therefore, the preparation and characterization of adsorptive media becomes the first and foremost step in water treatment using adsorption technology. $\mathrm{TiO}_{2}$ has been successfully used as an adsorbent for As removal from drinking water and wastewater [5,10-12]. Activated alumina (AA) is an EPA standard and a widely used adsorbent for defluoridation. However, AA exhibits well-known limitations, including a reduced $\mathrm{F}$ removal efficiency at $\mathrm{pH}>6$, and the release of $\mathrm{Al}$ $[2,13,14]$. Recently, lanthanum (La) impregnated materials have been proven to be the most promising $\mathrm{F}$ adsorbent due to the specific affinity of La sites with $F$ ions [15-18].

However, a limited number of studies have paid attention to developing effective adsorbents for the simultaneous removal of As(III) and F [19-21]. Recently, La-impregnated activated alumina (LAA) has been synthesized for As(III) $(9.23 \mathrm{mg} / \mathrm{g})$ and $\mathrm{F}$ ( $16.9 \mathrm{mg} / \mathrm{g}$ ) adsorption, with both As(III) and F occupying the sites on La rather than on $\mathrm{Al}[15,22]$. This result indicates that the impregnation of amorphous La oxide on AA may mask the Al sites, and thus As(III) and F have to compete for limited La sites. To take advantage of composite materials while avoiding the limitations of impregnation, we hypothesized that the orientated growth of La oxide on certain $\mathrm{TiO}_{2}$ facets with matched lattice spacing would be a feasible approach to synthesizing hybrid materials with both exposed $\mathrm{Ti}$ and La sites. Although this $\mathrm{TiO}_{2}$-La hybrid material has not been examined before, the synergetic effects of coexisting Ti and La sites enable it as an efficient adsorbent for the simultaneous removal of As(III) and $\mathrm{F}$.

As a proof-of-concept study herein, the purpose of this study was to construct a composite adsorbent with La oxide exhibiting orientated growth on $\mathrm{TiO}_{2}$ for simultaneous and effective removal of $\mathrm{As}(\mathrm{III})$ and $\mathrm{F}$. The molecular level interaction mechanism on this novel granular adsorbent was explored using multiple complementary techniques including extended X-ray absorption fine structure (EXAFS) spectroscopy and density function theory (DFT) calculations. The insights gained from this study further our understanding of the simultaneous removal mechanisms of $\mathrm{As}(\mathrm{III})$ and $\mathrm{F}$ on hybrid $\mathrm{TiO}_{2}$-La materials.

\section{Material and methods}

\subsection{Materials}

All chemicals used in this study were of analytical grade. Stock solutions containing $5000 \mathrm{mg} / \mathrm{L}$ of $\mathrm{As}$ (III) and $\mathrm{F}$ were prepared by dissolving $\mathrm{NaAsO}_{2}$ (Fisher Sci., US) and NaF in deionized (DI) water, respectively. A $1 \mathrm{M}$ La stock solution was prepared by dissolving La $\left(\mathrm{NO}_{3}\right)_{3} \cdot 6 \mathrm{H}_{2} \mathrm{O}$ in DI water, and the $\mathrm{pH}$ was adjusted to 6.0 using $\mathrm{NH}_{3} \cdot \mathrm{H}_{2} \mathrm{O}$.

\subsection{Synthesis of $\mathrm{TiO}_{2}$-La composite}

$\mathrm{TiO}_{2}$ with exposed $\{100\}$ facets used in this study was prepared via the hydrolysis of titanyl sulfate, then treated with $\mathrm{NaOH}$. The detailed procedures are presented in the Supplementary Information (SI). $\mathrm{TiO}_{2}$-La composite was prepared by orientated La growth on the obtained $\{100\}$-faceted $\mathrm{TiO}_{2}$. Specifically, a mixture of $150 \mathrm{mg} \mathrm{TiO}{ }_{2}$ and La stock solution was sonicated for $3 \mathrm{~h}$, and then calcined for $4 \mathrm{~h}$ at $400{ }^{\circ} \mathrm{C}$ in the muffle. After the obtained granules were ground and sieved, the material was washed with DI water until the conductivity was below $100 \mu \mathrm{S} / \mathrm{cm}$, and then dried in an oven at $60{ }^{\circ} \mathrm{C}$. The $60-80$ mesh $(180-250 \mu \mathrm{m})$ granular $\mathrm{TiO}_{2}-$ La material was used in the adsorption experiments.

\subsection{Characterization}

The BET specific surface area and Barrett-Joyner-Halenda (BJH) pore size distribution were determined from $\mathrm{N}_{2}$ adsorptiondesorption isotherms using an automated gas sorption instrument (Quantachrome Instruments, U.S.). The crystal structure was determined by XRD using an X'Pert PRO diffractometer (PANalytical, Netherlands) with $\mathrm{Cu} \mathrm{K} \alpha$ radiation. The surface morphology was examined using an FE-SEM with an Oxford energy dispersive Xray spectroscopy (EDX) analyzer (SU-8000, Hitachi), and the acceleration voltage was set at $5.0 \mathrm{kV}$. The crystal morphology was characterized using an HRTEM (JEM-2100F, JEOL) with an acceleration voltage of $200 \mathrm{kV}$. FTIR spectra were collected on a ThermoNicolet iS50 FTIR spectrometer with a deuterated triglycine sulfate (DTGS) detector. Raman spectra were obtained on a Horiba JY HR800 Raman spectrometer with an excitation wavelength at $532 \mathrm{~nm}$. X-ray photoelectron spectroscopy (XPS) was analyzed on a Thermo SCIENTIFIC ESCALAB 250 spectrometer with Al Ka X-ray radiation at $1486.8 \mathrm{eV}$. The XPS data processing and peak fitting were performed using the XPSPeak 4.0 software package. The granule strength was measured to be $45 \mathrm{~N}$ by a particle strength tester (Haibo, China). The pHpzc of $\mathrm{TiO}_{2}$ and $\mathrm{TiO}_{2}$-La were determined using a Zetasizer Nano ZS (Malvern Instrument Ltd., UK) with suspensions containing either $0.2 \mathrm{~g} / \mathrm{L} \mathrm{TiO}_{2}$ or $\mathrm{TiO}_{2}$ - $\mathrm{La}$ in $0.04 \mathrm{M} \mathrm{NaCl}$.

\subsection{Adsorption experiments}

Batch adsorption experiments were performed to compare the adsorption effectiveness of $\mathrm{TiO}_{2}$-La impregnated with different concentrations of $\mathrm{La}\left(\mathrm{NO}_{3}\right)_{3}$. In a typical experiment, $80 \mathrm{mg} \mathrm{TiO} 2^{-}$ La composite for $\mathrm{TiO}_{2}$ impregnated with different concentrations of $\mathrm{La}\left(\mathrm{NO}_{3}\right)_{3},-0,0.1,0.2,0.3,0.4,0.5$, and $0.6 \mathrm{mmol}$, respectively-, were mixed with $40 \mathrm{~mL}$ of either $1.5 \mathrm{mg} / \mathrm{L} \mathrm{As}(\mathrm{III})$ or $2.0 \mathrm{mg} / \mathrm{L} \mathrm{F}$ solution at $\mathrm{pH} 7$. A background electrolyte of $0.04 \mathrm{M} \mathrm{NaCl}$ was used in the experiment. $\mathrm{HCl}$ and $\mathrm{NaOH}$ were used to adjust the $\mathrm{pH}$. The results shown in Fig. $\mathrm{S} 1$ demonstrate that $\mathrm{TiO}_{2}$-La material with $0.5 \mathrm{mmol} \mathrm{La}\left(\mathrm{NO}_{3}\right)_{3}$ exhibited high adsorption densities for As(III) and $\mathrm{F}$, thus this material was used for further adsorption experiments.

Adsorption isotherm experiments were performed to determine the $\mathrm{As}(\mathrm{III})$ and $\mathrm{F}$ adsorption capacities on the $\mathrm{TiO}_{2}$ - $\mathrm{La}$ in a $0.04 \mathrm{M}$ $\mathrm{NaCl}$ solution. Suspension samples containing either $0.1-$ $2500 \mathrm{mg} / \mathrm{L} \mathrm{As}(\mathrm{III})$ or $0.5-2830 \mathrm{mg} / \mathrm{L} \mathrm{F}$ and $2 \mathrm{~g} / \mathrm{L} \mathrm{TiO}_{2}$-La were adjusted to $\mathrm{pH} 7$ with $\mathrm{NaOH}$ and $\mathrm{HCl}$. The adsorption kinetics on $2 \mathrm{~g} / \mathrm{L} \mathrm{TiO}_{2}$-La were studied at $\mathrm{pH} 7$ in $1 \mathrm{~L}$ of $0.04 \mathrm{M} \mathrm{NaCl}$ solution with initial either $1.7 \mathrm{mg} / \mathrm{L} \mathrm{As}(\mathrm{III})$ or $2.4 \mathrm{mg} / \mathrm{L} \mathrm{F}$. The adsorption envelope experiments with $2.5,25$, and $250 \mathrm{mg} / \mathrm{L} \mathrm{As}(\mathrm{III})$ or $\mathrm{F}$ on $2 \mathrm{~g} / \mathrm{L} \mathrm{TiO}_{2}$-La were conducted as a function of the solution $\mathrm{pH}$. The $\mathrm{pH}$ of the suspension in $0.04 \mathrm{M} \mathrm{NaCl}$ was adjusted to desired $\mathrm{pH}$ values in the range of $2-12$ using $\mathrm{NaOH}$ and $\mathrm{HCl}$. $\mathrm{As}(\mathrm{III})$ and $\mathrm{F}$ coadsorption experiments were conducted to determine the adsorption performance as a function of As(III), F concentrations, and $\mathrm{pH}$ conditions. The bottles for adsorption experiments were covered with aluminum foil to prevent light exposure. After the samples were mixed on a rotator for $24 \mathrm{~h}$, the final $\mathrm{pH}$ was measured and the suspensions were filtered through a $0.22-\mu \mathrm{m}$ membrane filter for analysis.

The measurement of soluble As was performed using a furnace atomic absorption spectrometer (FAAS, Perkin-Elmer AAS-800). The $\mathrm{F}$ concentration was measured using an $\mathrm{F}$ ion-selective electrode (Orion, Thermo Fisher Sci., US).

The adsorption isotherm was simulated with Langmuir model and expressed as Eq. (1):

$\frac{C_{e}}{q_{e}}=\frac{1}{q_{m} \times K}+\frac{C e}{q_{m}}$ 
where $q_{m}(\mathrm{mg} / \mathrm{g})$ is the maximum adsorption capacity; $q_{e}$ is the equilibrium adsorption density with certain equilibrium concentration of $C e(\mathrm{mg} / \mathrm{L})$ for adsorbate in the solution; and $K(\mathrm{~L} / \mathrm{mg})$ is the adsorption equilibrium constant.

The adsorption kinetics was modeled by pseudo-second order kinetics, and was calculated using Eq. (2):

$\frac{t}{q_{t}}=\frac{t}{q_{e}}+\frac{1}{k \times q_{e}^{2}}$

where $q_{t}$ and $q_{e}$ are the adsorption density $(\mathrm{mg} / \mathrm{g})$ at time $t$ and at equilibrium, respectively; and $k(\mathrm{~g} /(\mathrm{mg} \mathrm{h}))$ is the rate constant.

\subsection{Micro-beam $X$-ray fluorescence $(\mu-X R F)$ analysis}

The $\mu$-XRF sample was prepared with $100 \mathrm{mg} / \mathrm{L} \mathrm{As}(\mathrm{III}), 250 \mathrm{mg} /$ $\mathrm{LF}$, and $2 \mathrm{~g} / \mathrm{L} \mathrm{TiO}_{2}$-La in $0.04 \mathrm{M} \mathrm{NaCl}$ at $\mathrm{pH}$ 7. The spent media was freeze-dried and deposited onto Kapton tape. The $\mu$-XRF maps were acquired on beamline $15 \mathrm{U}$ at Shanghai Synchrotron Radiation Facility (SSRF), China. The monochromator was set at $14 \mathrm{keV}$ with the beam as $3 \times 3 \mu \mathrm{m}^{2}$ and the dwell time per pixel was $0.3 \mathrm{~s}$. The step size was $3 \mu \mathrm{m}$. The peak intensities for As, Ti, and La were collected at each pixel of $\mu$-XRF maps that were $67 \times 67 \mu \mathrm{m}^{2}$ in size.

\subsection{EXAFS study}

The samples from coadsorption experiments were freeze-dried and ground to 200 mesh, and then sealed between two layers of Kapton tape. The As K-edge $(11,867 \mathrm{eV})$ spectra were collected on beamline 01C1 at the National Synchrotron Radiation Research Center (NSRRC) in Taiwan. The spectra were acquired with a standard Lytle detector at cryogenic temperature ( $77 \mathrm{~K}$ ) using a helium cryostat to prevent beam-induced oxidation. An energy range of -200 to $1000 \mathrm{eV}$ from the K-edge was used to acquire the spectra. To improve the signal-to-noise ratio, three to five scans were collected for each sample, inspected for overall quality, and averaged. The EXAFS data was analyzed using the Athena and Artemis programs in the Demeter computer package [23]. The analysis procedure was similar to that in our previous studies [11,24], and is detailed in the SI.

\subsection{DFT calculations}

The density function theory (DFT)-based geometry optimization and adsorption energy of As(III) and F surface complexes were calculated using the Castep package in Materials Studio 7.0 (Accelrys, San Diego, CA). The model building was detailed in the SI. A planewave cutoff energy of $340 \mathrm{eV}$ was selected and the core electrons were treated using ultrasoft pseudopotentials. The generalized gradient approximation (GGA) approach of Perdew-Burke-Ernzerhof (PBE) was employed to calculate the exchange-correlation energy. The $k$-point over the Brillouin zone was set as a $2 \times 2 \times 1$ grid. The geometry optimization was calculated with the BFGS method until meeting the convergence criteria, $1.0 \times 10^{-6}$ and $1.0 \times 10^{-5} \mathrm{eV} /$ atom, respectively, for SCF and energy tolerances [25]. All atoms were relaxed during calculations.

The adsorption energies ( $E_{\text {ads }}$ ) of $\mathrm{As}$ (III) and $\mathrm{F}$ molecules was calculated according to the following Eq. (3):

$\mathrm{E}_{\mathrm{ads}}=\mathrm{E}_{\mathrm{mol}+\text { surf }}-\left(\mathrm{E}_{\mathrm{surf}}+\mathrm{E}_{\mathrm{mol}}\right)$

where $E_{\text {mol+surf }}$ is the total energy of the surface complexes; $E_{\text {surf }}$ is the energy of the isolated $\mathrm{TiO}_{2}\{100\}$ and $\mathrm{LaCO}_{3} \mathrm{OH}\{011\}$ facets; and $\mathrm{E}_{\mathrm{mol}}$ represents the energy of isolated $\mathrm{As}(\mathrm{III})$ and $\mathrm{F}$ molecules. Note that a negative value for $\mathrm{E}_{\mathrm{ads}}$ suggests a stable adsorption configuration.

\section{Results and discussion}

\subsection{Characterization of granular $\mathrm{TiO}_{2}$-La composite}

The morphology and structural properties of the $\mathrm{TiO}_{2}$-La and control samples were characterized using SEM, TEM, and EDX (Fig. 1). The SEM and TEM images of $\mathrm{TiO}_{2}$ (Fig. 1a-c) showed that the nanorod $\mathrm{TiO}_{2}$ of $c a .750 \mathrm{~nm}$ was tetragonal spindle exposed mostly with high-energy $\{100\}$ facets [26]. The thermodynamically stable $\{101\}$ facets existed only on the tip of the spindle with a lattice spacing of $3.5 \AA$ [27]. The images of $\mathrm{TiO}_{2}$-La (Fig. 1e-g) showed that $\mathrm{LaCO}_{3} \mathrm{OH}$ had orientated growth on $\mathrm{TiO}_{2}$ with their matched lattice spacing $(1.9 \AA)$ between the $\mathrm{TiO}_{2}$ ( 2000$)$ plane and $\mathrm{LaCO}_{3} \mathrm{OH}\left(\begin{array}{ll}0 & 3\end{array}\right)$ plane [28]. Considering the same atomic coor-

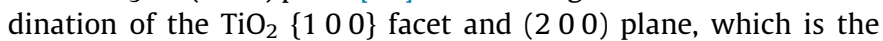
same as the $\mathrm{LaCO}_{3} \mathrm{OH}$ crystal (for $\left\{\begin{array}{lll}0 & 1 & 1\end{array}\right\}$ facet and (0 $\left.\begin{array}{lll}0 & 3\end{array}\right)$ plane), we used unified facet to represent the crystal plane. The EDX spectra (Fig. 1h) confirmed that the sample is composed of Ti, La, C, and $\mathrm{O}$ elements. The control sample that was synthesized without addition of $\mathrm{TiO}_{2}$ was nanorod $\mathrm{La}(\mathrm{OH})_{3}$, and composed of $\mathrm{La}$ and $\mathrm{O}$ elements with exposed $\left\{\begin{array}{lll}1 & 0 & 1\end{array}\right\}$ facets (Fig. 1i-1), which highlights the significance of $\mathrm{TiO}_{2}$ facet for the synthesis of hybrid $\mathrm{TiO}_{2}-\mathrm{La}$ materials.

XPS was used to inspect the surface composition and chemical states of the $\mathrm{TiO}_{2}$-La material. Each of the binding energies obtained in the XPS analysis were calibrated using the C 1s peak at $284.60 \mathrm{eV}$ from contamination as reference. The survey XPS spectrum of the prepared $\mathrm{TiO}_{2}$-La sample (Fig. 2a) indicates the presence of $\mathrm{Ti}, \mathrm{La}, \mathrm{O}$, and $\mathrm{C}$, in accord with the result of EDX (Fig. 1h). The XPS spectra of the Ti 2p core level region of the sample is shown in Fig. 2b. The two peaks at about $458.3 \mathrm{eV}$ and $464.0 \mathrm{eV}$ can be assigned to the Ti $2 \mathrm{p}_{3 / 2}$ and Ti $2 \mathrm{p}_{1 / 2}$ spin orbital splitting photoelectrons in the $\mathrm{Ti}^{4+}$ chemical state $[25,29]$, respectively. Fig. 2c shows the La 3d XPS spectrum of the prepared sample. The electron binding energy values are observed at $835.1 \mathrm{eV}$ and $851.7 \mathrm{eV}$, corresponding to the main peaks ( $3 \mathrm{~d}^{0} 4 \mathrm{f}$ configuration) of La $3 d_{5 / 2}$ and La $3 d_{3 / 2}$ with the shake-up peaks ( $3 d^{0} 4 f^{1}$ configuration) located at $838.8 \mathrm{eV}$ and $855.6 \mathrm{eV}$, respectively, which correspond to the $\mathrm{La}(\mathrm{III})$ oxidation state $[28,30]$. The binding energies at $531.8 \mathrm{eV}$ and $529.8 \mathrm{eV}$ in $\mathrm{O} 1 \mathrm{~s}$ spectra (Fig. 2d) are related to lattice oxygen in $\mathrm{LaCO}_{3} \mathrm{OH}$ and $\mathrm{TiO}_{2}[31,32]$, respectively. The $\mathrm{C} 1 \mathrm{~s}$ spectrum (Fig. 2e) exhibits peaks at $289.8 \mathrm{eV}$ and $284.60 \mathrm{eV}$, corresponding to the carbonate and carbon contamination as reference, respectively [28].

The XRD patterns of $\mathrm{TiO}_{2}$-La shown in Fig. S2 indicate that all diffraction peaks can be indexed to the tetragonal $\mathrm{TiO}_{2}$ (JCPDS: 65-5714) and orthorhombic $\mathrm{LaCO}_{3} \mathrm{OH}$ (JCPDS: 49-0981). FTIR and Raman characterizations suggest that the impregnation of La composite on $\mathrm{TiO}_{2}$ had no change on the $\mathrm{TiO}_{2}$ structure (Fig. S3). The BET surface specific area of $\mathrm{TiO}_{2}$-La was determined to be approximately $23.7 \mathrm{~m}^{2} / \mathrm{g}$, and the $\mathrm{BJH}$ pore size distribution ranged from 35 to $42 \mathrm{~nm}$ with the peak located at ca.38 nm (Fig. S4). TGA analysis indicated that the material exhibited high thermostability with $6.3 \%$ weight loss after heating at $400{ }^{\circ} \mathrm{C}$ (Fig. S5). Detailed descriptions of the characterization results are presented in the SI.

\subsection{Heterostructure of $\mathrm{TiO}_{2}-\mathrm{La}$}

To further elucidate the significant role of $\mathrm{TiO}_{2}\{100\}$ facet in synthesizing $\mathrm{TiO}_{2}$-La, we compared the hybrid materials by impregnating $\mathrm{La}$ on $\mathrm{TiO}_{2}$ with three index facets of $\{100\},\{001\}$, and $\{101\}$ (Fig. S6). Our results clearly demonstrate that $\mathrm{LaCO}_{3} \mathrm{OH}$ showed orientated growth only on $\{100\}$-faceted $\mathrm{TiO}_{2}$ with La contents up to $26.4 \%$ (Fig. 1), which is an order of magnitude higher than that on $\{101\}$-faceted (3.9\%) and $\{001\}$-faceted $(6.9 \%) \mathrm{TiO}_{2}$ 

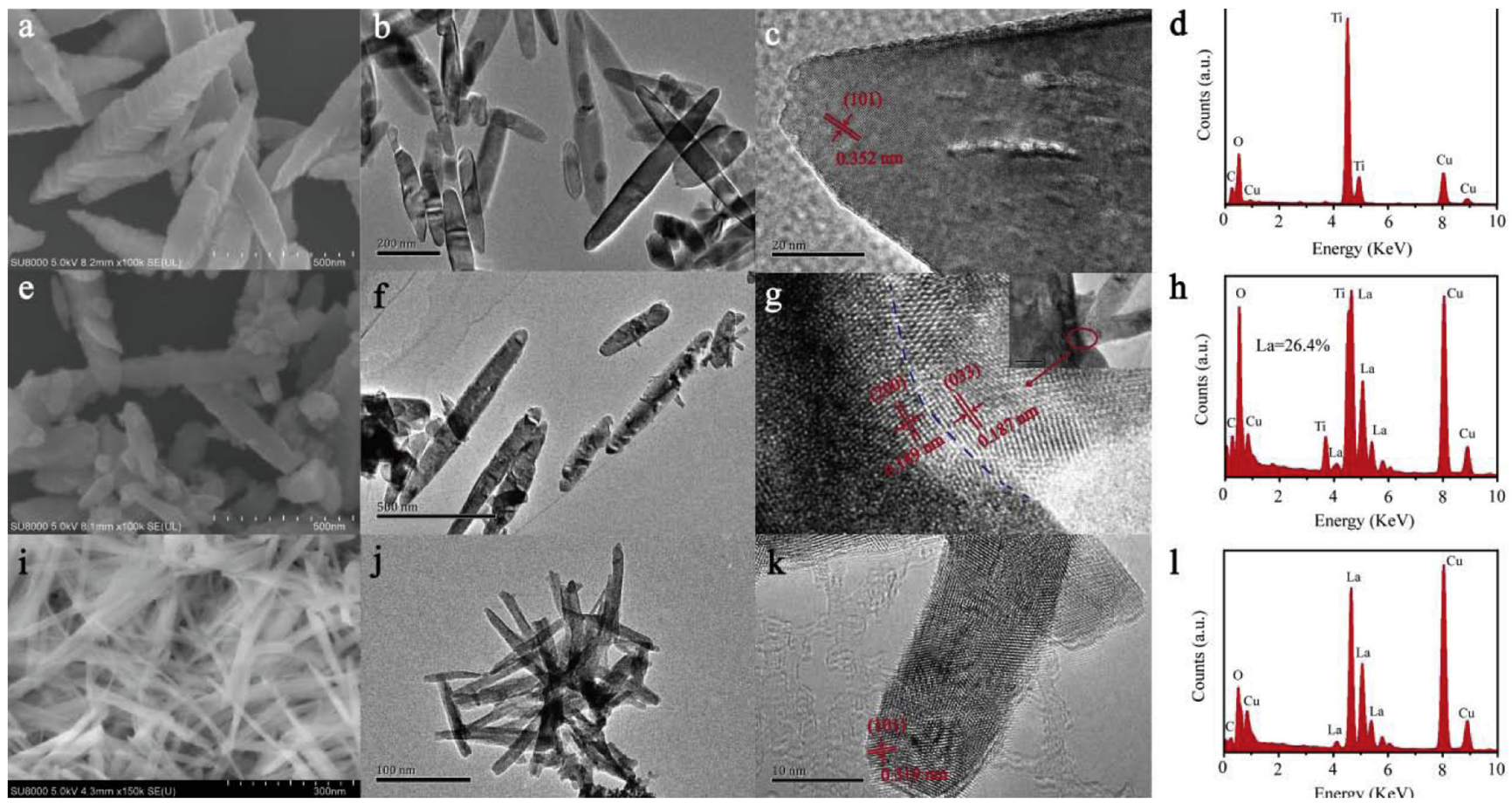

Fig. 1. SEM, TEM, and EDX characterization of $\{100\}$-faceted $\mathrm{TiO}_{2}(\mathrm{a}-\mathrm{d}), \mathrm{TiO}_{2}-\mathrm{La}(\mathrm{e}-\mathrm{h})$, and $\mathrm{La}(\mathrm{OH})_{3}(\mathrm{i}-\mathrm{l})$.
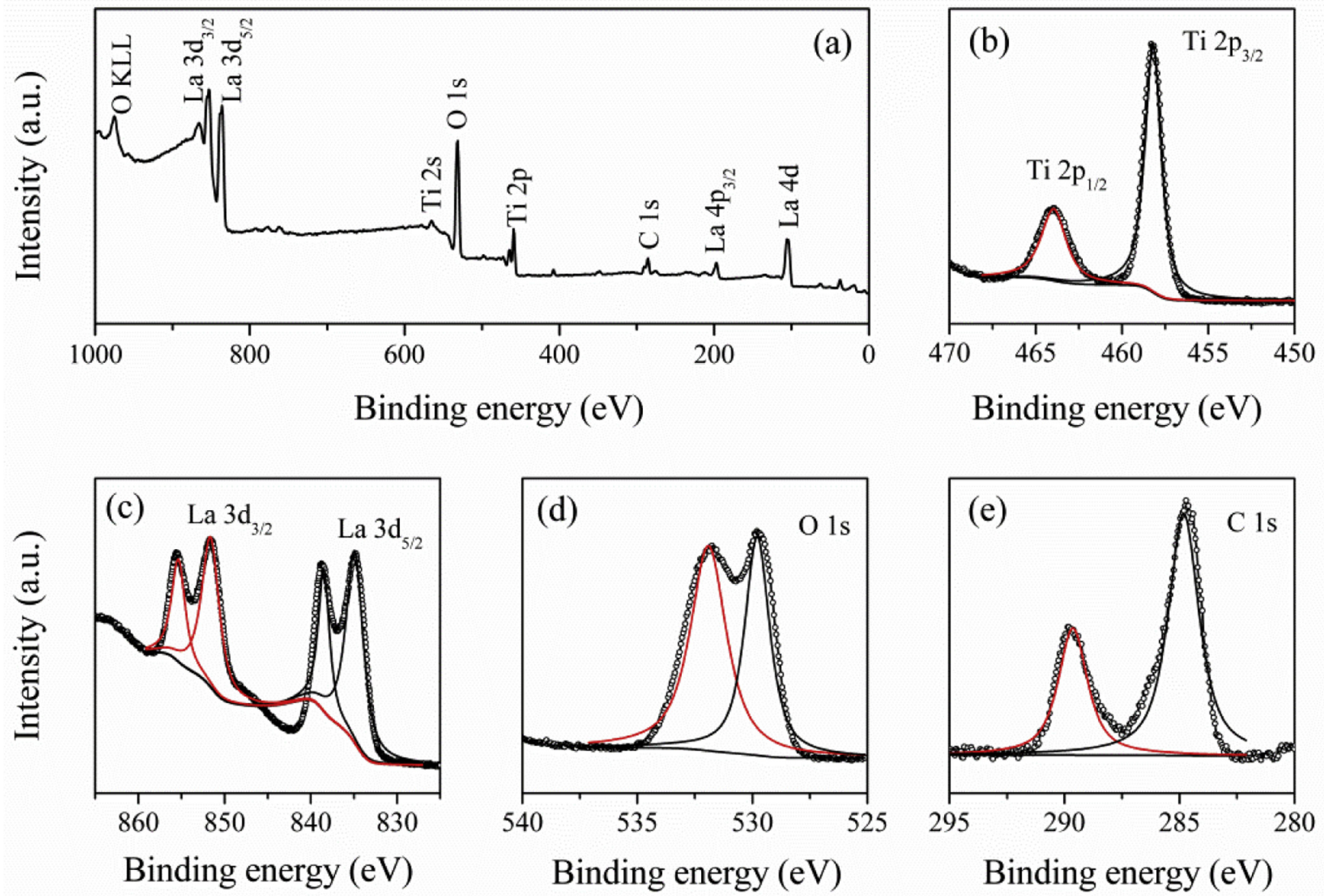

Fig. 2. XPS spectra of $\mathrm{TiO}_{2}$-La sample (a), and of the core levels of $\mathrm{Ti} 2 \mathrm{p}$ (b), La 3d (c), O 1s (d), and C 1s (e). 
(Fig. S6). This unique advantage of $\{100\}$ facet can be attributed to two reasons. Firstly, the $\mathrm{TiO}_{2}\{100\}$ facets favor $\mathrm{CO}_{2}$ adsorption $\left(\mathrm{E}_{\mathrm{ads}}=-0.1 \mathrm{eV}\right)$ and subsequently the formation of $\mathrm{CO}_{3}^{2-}$ on the surface (Fig. 3a). Secondly, only the lattice spacing (1.9 $\AA$ ) and parallel crystal orientation of $\{100\}$ facet (Fig. 1g), not of $\{101\}$ (3.5 $)$ and $\{001\}$ facets (perpendicular orientation with $\{100\}$ facet), match that of $\mathrm{LaCO}_{3} \mathrm{OH}\{011\}$ facets.

The formation of $\mathrm{LaCO}_{3} \mathrm{OH}$ can be attributed to the following reaction Eqs. (4)-(6), where $\mathrm{NH}_{3} \cdot \mathrm{H}_{2} \mathrm{O}$ is used to adjust $\mathrm{pH}$ of La $\left(\mathrm{NO}_{3}\right)_{3} \cdot 6 \mathrm{H}_{2} \mathrm{O}$ solution:

Surf- $\mathrm{O}^{2-}+\mathrm{CO}_{2}(\mathrm{~g})=$ Surf- $-\mathrm{CO}_{3}^{2-}$

$\mathrm{NH}_{3} \cdot \mathrm{H}_{2} \mathrm{O}=\mathrm{NH}_{4}^{+}+\mathrm{OH}^{-}$

$\mathrm{La}^{3+}+\mathrm{OH}^{-}+$Surf- $\mathrm{CO}_{3}^{2-}=$ Surf- $\mathrm{LaCO}_{3} \mathrm{OH}$

The geometry-optimized $\mathrm{TiO}_{2}$-La heterostructure is presented in Fig. 3b. The results suggest that new $\mathrm{Ti}-\mathrm{O}$ and $\mathrm{La}-\mathrm{O}$ bonds were formed in the heterostructure interface. The formation of new bonds is a Lewis acid-base reaction because surface $\mathrm{Ti}^{4+}$ and $\mathrm{La}^{3+}$ atoms shared an electron pair of coordinated $\mathrm{O}^{2-}$ that existed on the surface to form $\mathrm{Ti}-\mathrm{O}$ and $\mathrm{La}-\mathrm{O}$ bonds, as elucidated by our partial density of states (PDOS) analysis. The overlap of PDOS in Fig. $3 \mathrm{c}$ and $\mathrm{d}$ indicates that the five-coordinated $\mathrm{Ti}$ atoms on the $\mathrm{TiO}_{2}$ facets covalently bonded with $\mathrm{O}$ atoms from La oxides, as evidenced by the electron sharing between the $0-2 p$ and Ti-3d orbitals [25]. The newly formed La-O bond was mainly attributed to the electron sharing between the $0-2 p$ and La- $5 d$ orbitals.

The $\mathrm{TiO}_{2}$-La heterostructure provides more La adsorption sites than pristine $\mathrm{TiO}_{2}$ for $\mathrm{As}(\mathrm{III})$ and $\mathrm{F}$ adsorption. The adsorption comparison between $\mathrm{TiO}_{2}$ and hybrid $\mathrm{TiO}_{2}$-La with different facets is summarized in Fig. S7 and highlights two observations. First, As (III) adsorption on $\{100\}$-faceted $\mathrm{TiO}_{2}$-La was enhanced by $40.1 \%$ compared with $\mathrm{TiO}_{2}$, whereas it was reduced by $2 \%$ on other two-faceted $\mathrm{TiO}_{2}$-La materials. Though all three of the faceted $\mathrm{TiO}_{2}$-La hybrid materials enhanced $\mathrm{F}$ removal compared with pristine $\mathrm{TiO}_{2},\{100\}$-faceted $\mathrm{TiO}_{2}$-La (79.2\% increase) exhibited a significant superiority to $\{001\}$-faceted $(7.4 \%)$ and $\{101\}$-faceted (7.6\%) $\mathrm{TiO}_{2}$-La (Fig. S7a). Second, the adsorption density of $\mathrm{As}(\mathrm{III})$ and $\mathrm{F}$ in the unit of molecules $/ \mathrm{nm}^{2}$ on $\{100\}$-faceted $\mathrm{TiO}_{2}$-La ( 0.25 for $\mathrm{As}(\mathrm{III}), 1.18$ for $\mathrm{F}$ ) was an order of magnitude higher than the other two faceted $\mathrm{TiO}_{2}$-La materials (0.016-0.029 for As(III), 0.021-0.029 for F, Fig. S7b). Due to its unique advantage, we focus our study on $\{100\}$-faceted $\mathrm{TiO}_{2}$-La hybrid material.

\subsection{Adsorption experiments}

The adsorption isotherms of $\mathrm{As}(\mathrm{III})$ and $\mathrm{F}$ on $\mathrm{TiO}_{2}$-La conformed to the Langmuir model, and the fitting parameters are shown in the inset of Fig. 4a. The results suggested that the maximum adsorption capacities $\left(q_{m}\right)$ for As(III) and F followed the order of $q_{m}(\mathrm{As})$ $(114 \mathrm{mg} / \mathrm{g})>q_{m}(\mathrm{~F})(78.4 \mathrm{mg} / \mathrm{g})$. This is because two sites (mixed Ti and La sites) were available for As(III) adsorption, whereas only La site was responsible for $\mathrm{F}$ adsorption (vide infra). The $q_{m}$ for present studied $\mathrm{TiO}_{2}$-La composite is higher than other reported adsorbents with simultaneous As and $\mathrm{F}$ removal, such as E33P, $\mathrm{Al}_{2} \mathrm{O}_{3}, \mathrm{La}-\mathrm{Al}_{2} \mathrm{O}_{3}$ (LAA), Ti-La impregnated activated carbon (TLAC), $\mathrm{Al} / \mathrm{Fe}$-doped adsorbents, and modified cellulose fibers, with adsorption capacities in the range of $7.3-40 \mathrm{mg} / \mathrm{g}$ for As, and $2.3-100 \mathrm{mg} / \mathrm{g}$ for $\mathrm{F}[15,19-22]$.

The adsorption of $\mathrm{As}(\mathrm{III})$ and $\mathrm{F}$ on $\mathrm{TiO}_{2}$-La followed pseudosecond order kinetics $\left(R^{2}>0.98\right.$, Fig. $\left.4 b\right)$, suggesting that chemical adsorption is the rate-controlling step, which is further evidenced by our EXAFS and DFT study. The rate constant, $k$, for F adsorption was $0.51 \mathrm{~g} /(\mathrm{mg} \mathrm{h})$, which is slightly higher than that for $\mathrm{As}(\mathrm{III})$ $(0.43 \mathrm{~g} /(\mathrm{mg} \mathrm{h})$, Fig. $4 \mathrm{~b}$ inset). The faster kinetics of $\mathrm{F}$ may result from its smaller molecular size. Furthermore, the La sites, which are attributable to $\mathrm{F}$ uptake, have a short distance to access F molecules due to their orientated growth on the outside of the $\mathrm{TiO}_{2}$ surface. The $q_{e}$ in Fig. $4 \mathrm{~b}$ was the adsorption density with initial As(III) and $\mathrm{F}$ concentration of 1.7 and $2.4 \mathrm{mg} / \mathrm{L}$, respectively. The equilibrium concentration after adsorption was $0.23 \mathrm{mg} / \mathrm{L}$ for $\mathrm{As}(\mathrm{III})$ and $0.14 \mathrm{mg} / \mathrm{L}$ for $\mathrm{F}$, leading to $q_{e}(\mathrm{As})(0.8 \mathrm{mg} / \mathrm{g})<q_{e}(\mathrm{~F})(1.2 \mathrm{mg} / \mathrm{g})$. This
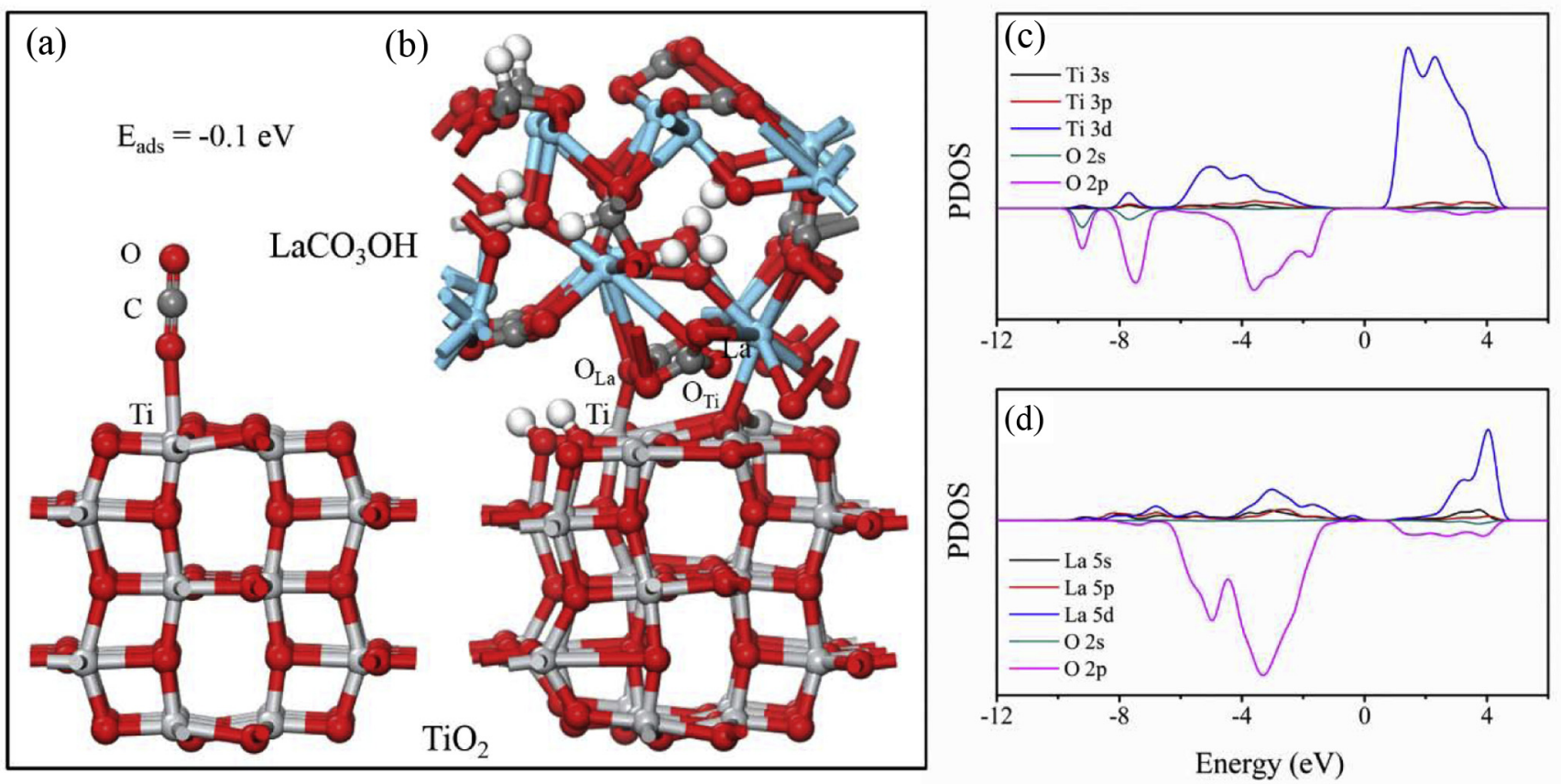

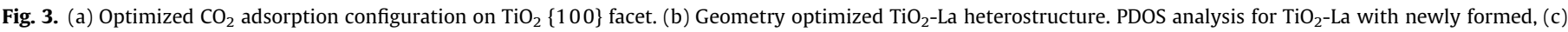
$\mathrm{Ti}-\mathrm{O}$ and (d) $\mathrm{La}-\mathrm{O}$ bond. $\mathrm{O}_{\mathrm{Ti}}$ and $\mathrm{O}_{\mathrm{La}}$ in (b) represent the $\mathrm{O}$ atoms on the $\mathrm{TiO}_{2}$ and $\mathrm{LaCO}_{3} \mathrm{OH}$ surfaces, respectively. 

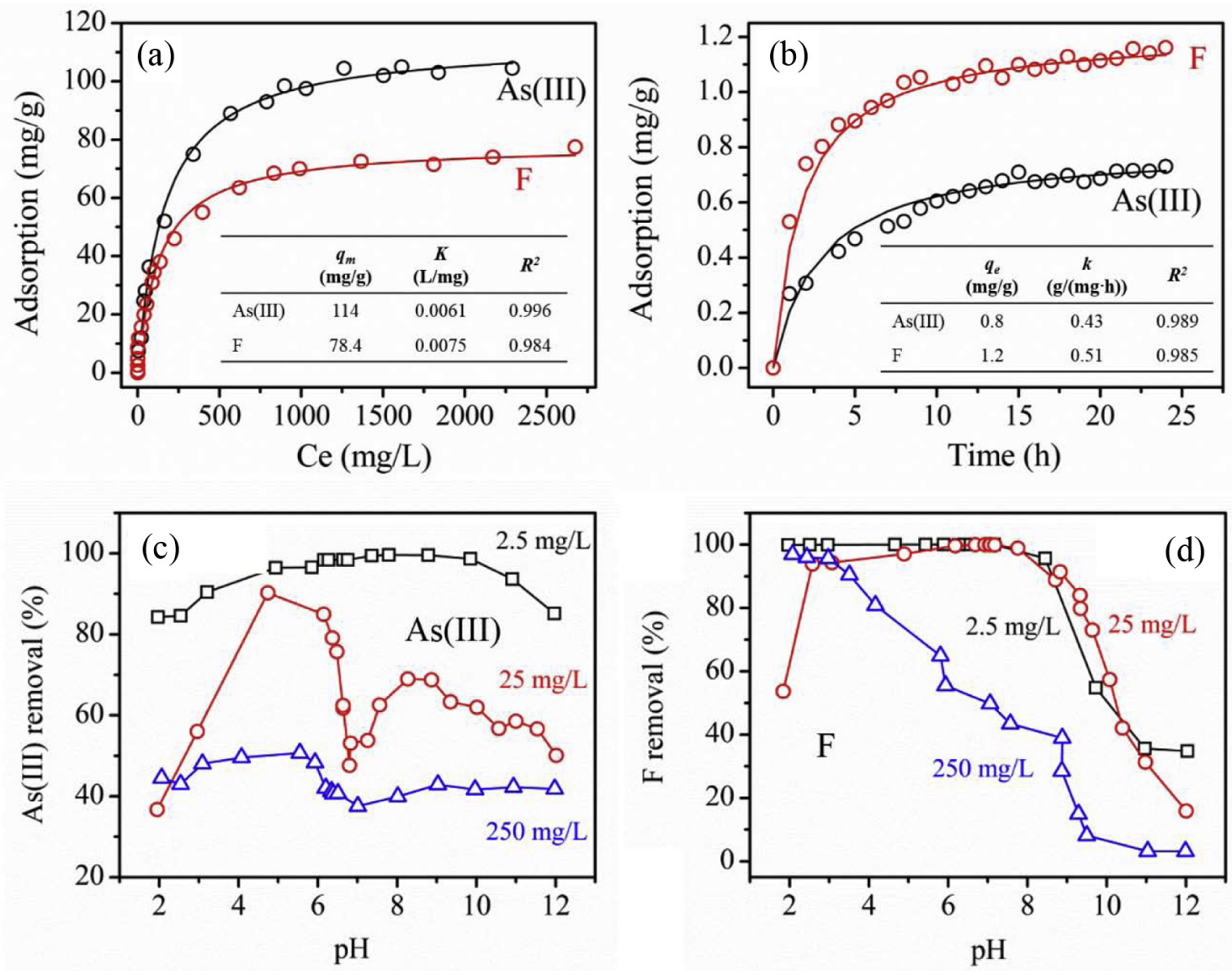

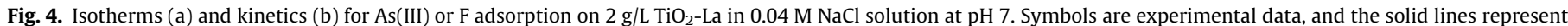

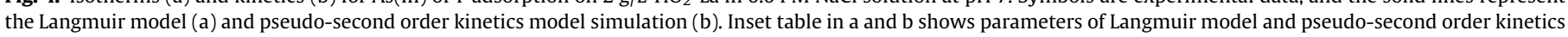
model. As(III) (c) and F (d) removal efficiency as a function of pH. The initial As(III) or F concentrations are $2.5 \mathrm{mg} / \mathrm{L}, 25 \mathrm{mg} / \mathrm{L}$, and $250 \mathrm{mg} / \mathrm{L}$, respectively.

(a) $\operatorname{As}($ III) adsorption ( $\mathrm{mg} / \mathrm{g}$ )

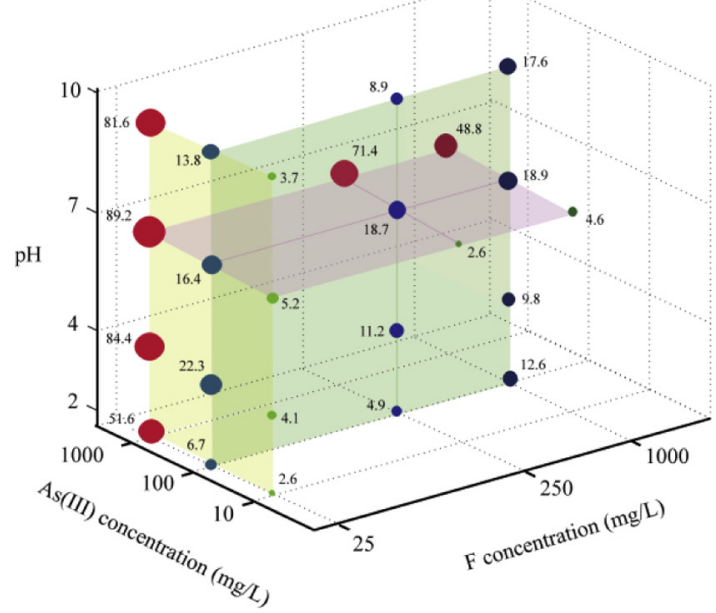

(b) F adsorption ( $\mathrm{mg} / \mathrm{g})$

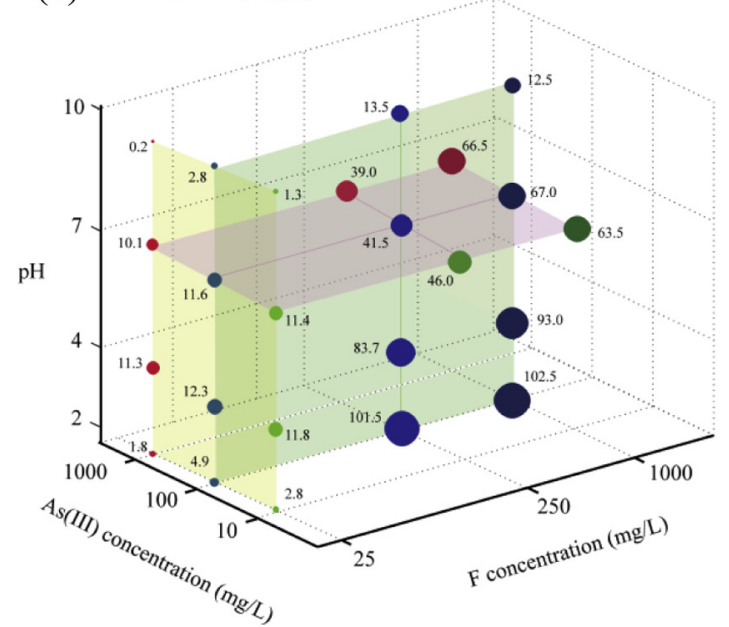

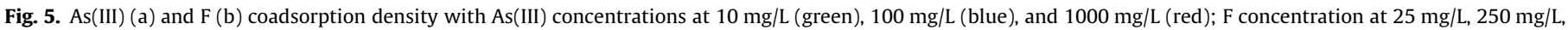

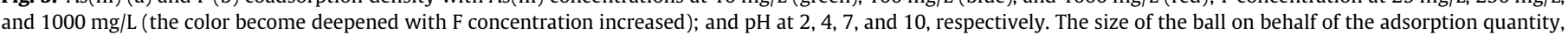
and the value was listed nearby the ball. (For interpretation of the references to colour in this figure legend, the reader is referred to the web version of this article.)

observation can be explained by lower initial As(III) concentration compared to that of $\mathrm{F}$.

The $\mathrm{As}(\mathrm{III})$ and $\mathrm{F}$ adsorption envelope experiments determined the percentage of $\mathrm{As}(\mathrm{III})$ and $\mathrm{F}$ adsorbed as a function of equilibrium $\mathrm{pH}$ (Fig. $4 \mathrm{c}$ and $\mathrm{d}$ ). $\mathrm{TiO}_{2}$-La exhibited a wide $\mathrm{pH}$ application range (3-9), removing $>90 \%$ of As(III) and $95 \%$ of $\mathrm{F}$ with their initial concentrations at $2.5 \mathrm{mg} / \mathrm{L}$. When the initial concentrations were increased to $25 \mathrm{mg} / \mathrm{L}$ and $250 \mathrm{mg} / \mathrm{L}$, an M-shaped curve for As(III) adsorption was observed with two adsorption maxima at pH's of about 4.8 and 8.5 (Fig. 4c), indicating the existence of two 
different adsorption sites on $\mathrm{TiO}_{2}$-La. One site was $\mathrm{TiO}_{2}$ that is responsible for $\mathrm{As}(\mathrm{III})$ adsorption at a low $\mathrm{pH}$ range from 3 to 7 , as evidenced by its low pHpzc at 3.7 (Fig. S8). The other site was on La-oxide that favorable at high $\mathrm{pH}$ range of $7-10$ with its $\mathrm{pHpzc}$ at 9.2 [22]. The $\mathrm{F}$ adsorption behaviors with increasing initial concentrations followed the characteristic of anion adsorption on single metal oxide $\left(\mathrm{LaCO}_{3} \mathrm{OH}\right)$, which is decreasing with the increasing $\mathrm{pH}$ (Fig. 4d).

\subsection{As(III) and F coadsorption experiments}

As(III) and $\mathrm{F}$ coadsorption experiments were performed to determine the effect of $\mathrm{pH}$ and $\mathrm{As}(\mathrm{III})$ and $\mathrm{F}$ concentrations. The results summarized in Fig. 5a indicate that with a low coexisting $\mathrm{F}(25 \mathrm{mg} / \mathrm{L})$ and $\mathrm{As}(\mathrm{III})(10 \mathrm{mg} / \mathrm{L})$ at $\mathrm{pH} 7$, the adsorption density

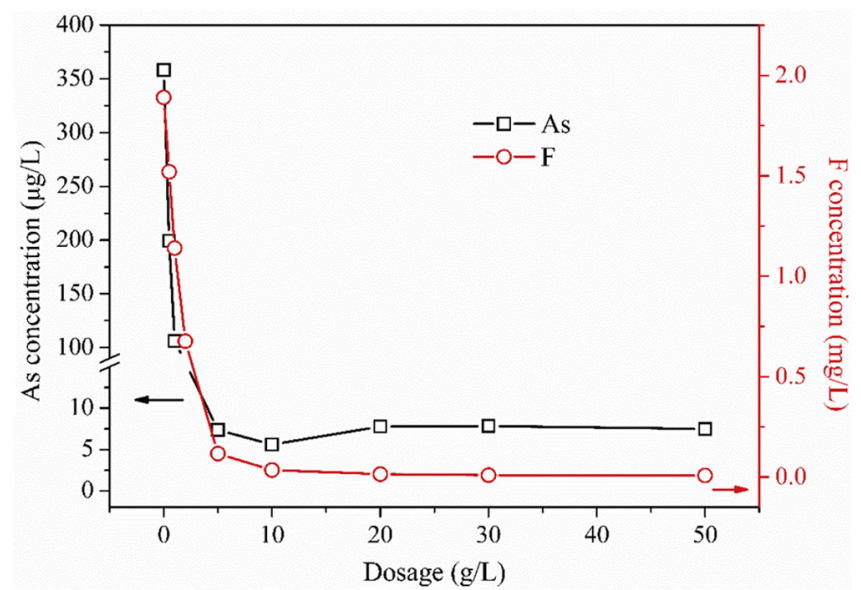

Fig. 6. As and $\mathrm{F}$ adsorption with different dosage of $\mathrm{TiO}_{2}$ - $\mathrm{La}$, ranging from 0 to $50 \mathrm{~g} / \mathrm{L}$. of $\mathrm{As}(\mathrm{III})$ was $5.2 \mathrm{mg} / \mathrm{g}$. The density was significantly increased to $89.2 \mathrm{mg} / \mathrm{g}$ with the increase of initial As(III) concentration up to $1000 \mathrm{mg} / \mathrm{L}$ (Fig. 5a, yellow panel). However, the As(III) adsorption density decreased from 89.2 to $48.8 \mathrm{mg} / \mathrm{g}$ with the increase in $\mathrm{F}$, albeit the initial $\mathrm{As}(\mathrm{III})$ concentration was increased as high as $1000 \mathrm{mg} / \mathrm{L}$ (Fig. 5a, purple panel). This result indicates that high concentrations of coexisting $\mathrm{F}$ can significantly influence As(III) adsorption in the presence of high initial As(III) concentrations. With initial As(III) concentrations decreased to $100 \mathrm{mg} / \mathrm{L}$, the $\mathrm{F}$ influence on As(III) adsorption was negligible (Fig. 5a, green panel), which can be attributed to the hybrid adsorption sites of Ti and La for As(III) adsorption (Fig. 4c). The observed trend agrees with the logic that $\mathrm{F}$ adsorption on La sites may exaggerate the steric hindrance for the access of $\mathrm{H}_{3} \mathrm{AsO}_{3}$ to the $\mathrm{TiO}_{2}$-La surface. As(III) adsorption in the $\mathrm{pH}$ range of 4-7 exhibited a higher adsorption density than that at $\mathrm{pH} 2$ and 10 , which is consistent with the results of $\mathrm{pH}$ edge (Fig. 4c).

The $\mathrm{F}$ adsorption density was about $11.0 \mathrm{mg} / \mathrm{g}$ with an initial $\mathrm{F}$ concentration of $25 \mathrm{mg} / \mathrm{L}$ at $\mathrm{pH} 7$, and the increase in the coexisting As(III) concentration from 10 to $1000 \mathrm{mg} / \mathrm{L}$ had no effect on $\mathrm{F}$ adsorption (Fig. 5b, yellow panel). When initial $\mathrm{F}$ concentration was increased to $1000 \mathrm{mg} / \mathrm{L}$, the F adsorption density significantly increased from 11.0 to $65.7 \mathrm{mg} / \mathrm{g}$. The coexisting As(III) had no effect on $\mathrm{F}$ adsorption (Fig. 5b, purple and green panels). F adsorption is $\mathrm{pH}$-dependent that the increase in $\mathrm{pH}$ decreases the $\mathrm{F}$ adsorption (Fig. 4d).

The hybrid $\mathrm{TiO}_{2}$-La material was used to remediate a real groundwater sample taken from Shanxi, China, with a concentration of $342 \mu \mathrm{g} / \mathrm{L} \mathrm{As}(\mathrm{III}), 16 \mu \mathrm{g} / \mathrm{L} \mathrm{As}(\mathrm{V})$, and $1.9 \mathrm{mg} / \mathrm{L} \mathrm{F}$ at $\mathrm{pH} 8.2$. Our results demonstrate an effective simultaneous removal of As and $\mathrm{F}$ using granular $\mathrm{TiO}_{2}$-La composite, where a dosage of $5 \mathrm{~g} / \mathrm{L}$ can provide As/F-safe drinking water (Fig. 6), which highlighted the environmental application of this $\mathrm{TiO}_{2}$-La composite.

Adsorption experiments showed a macroscopic picture of As(III) and $\mathrm{F}$ behaviors on the materials, mechanistic information,
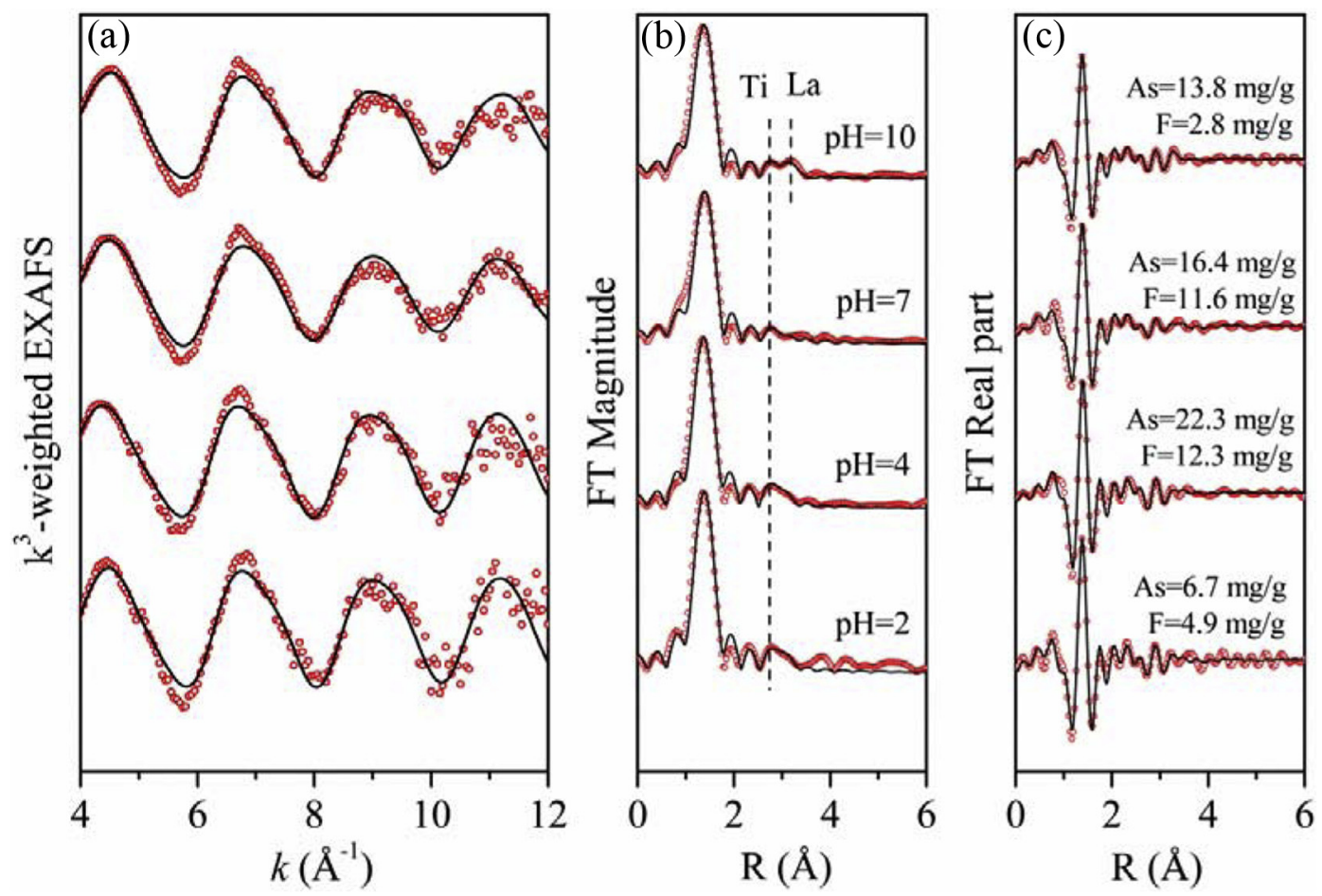

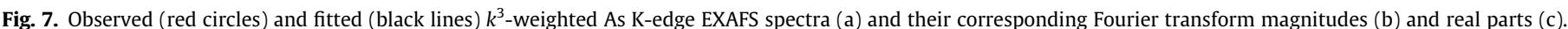

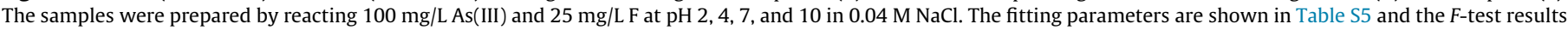
are shown in Table S9. (For interpretation of the references to colour in this figure legend, the reader is referred to the web version of this article.) 
however, cannot be explicitly derived from the above observations. Therefore, spectroscopic techniques were used to decipher the molecular-level mechanisms of $\mathrm{As}(\mathrm{III})$ and $\mathrm{F}$ adsorption on $\mathrm{TiO}_{2}$ - $\mathrm{La}$.

\subsection{Distribution of elements on $\mathrm{TiO}_{2}-\mathrm{La}$}

The distribution of As on nanomaterials has been studied by synchrotron-based $\mu$-XRF, and the results suggested that As was associated with $\mathrm{Ti}$ and La oxides (Fig. S9). The highly correlated $\mathrm{Ti}$ and $\mathrm{La}$ demonstrated that $\mathrm{LaCO}_{3} \mathrm{OH}$ was evenly distributed on $\mathrm{TiO}_{2}$ in $\mu \mathrm{m}$-size resolution provided by $\mu$-XRF. To further investigate the adsorption mechanism of $\mathrm{As}$ (III) and $\mathrm{F}$ on hybrid $\mathrm{TiO}_{2}-\mathrm{La}$ material, a molecular-level study including EXAFS and DFT was necessary.

\subsection{EXAFS study}

To explore the role of $\mathrm{Ti}$ and La sites on As(III) removal, we employed EXAFS to characterize the local coordination environment. The $k^{3}$-weighted As $K$-edge EXAFS spectra and corresponding Fourier transforms (FT) for As(III) and F coadsorption samples are presented in Figs. S10-12, and their fitting parameters are shown in Tables S1-4. For all samples, a strong FT signal at 1.78-1.79 was resolved corresponding to three As-O single scattering (SS) paths in the first shell. An As-O-O multiple scattering path within the $\mathrm{AsO}_{3}$ pyramid was included in the fitting without adding extra variables [24].

The second FT peak was ascribed to $1.8-2.1 \mathrm{Ti}$ atoms at 3.35$3.39 \AA$ (Table S1), which is in agreement with As(III) bidentate binuclear configurations on $\mathrm{TiO}_{2}$ [24]. Conversely, the As-La SS path for the second shell fitting resulted in unsatisfactory R-factors (0.018-0.031, Fig. S11, Table S2). The idea that Ti was in the second shell of As was further justified by the F-test. The confidence level of including the As-Ti path is 74.1-97.3\% (Table S4), higher than the required significance level of $67 \%$ [24]. In contrast, the confidence level with the inclusion of the As-La path was only $0-42.2 \%$ (Table S4), confirming that La atoms do not exist in the second shell of As. This analysis showed that As(III) mainly adsorbs on $\mathrm{Ti}$ sites of $\mathrm{TiO}_{2}$-La, and the coexisting $\mathrm{F}$ ions have no impact on the As(III) surface configuration.

The EXAFS results for $\mathrm{As}(\mathrm{III})$ and $\mathrm{F}$ co-adsorption samples at different pH's are shown in Figs. 7 and S13-15, and Tables S5-9. Interestingly, the sample at $\mathrm{pH}=10$ resulted in a second shell with mixed As-Ti and As-La paths, as evidenced by their high F-test (a)

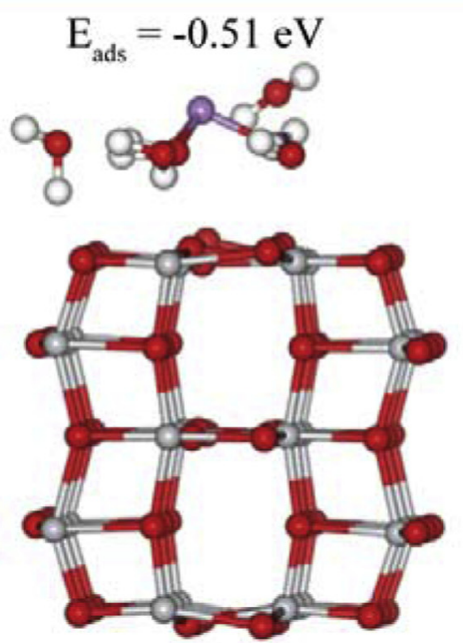

(d)

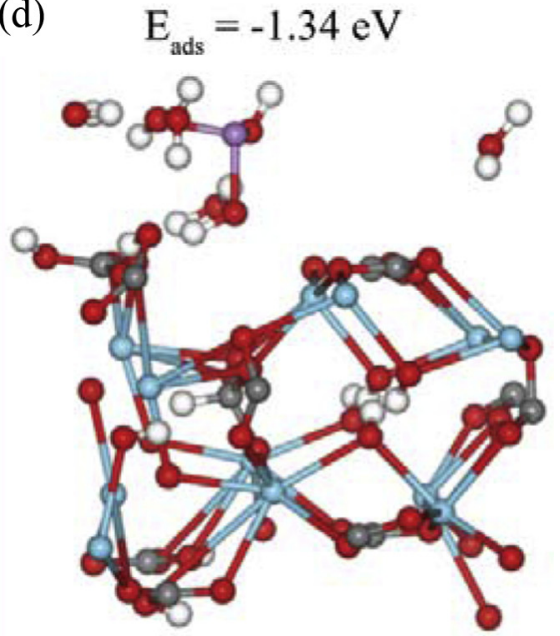

(b)

$$
\mathrm{E}_{\text {ads }}=0.70 \mathrm{eV}
$$

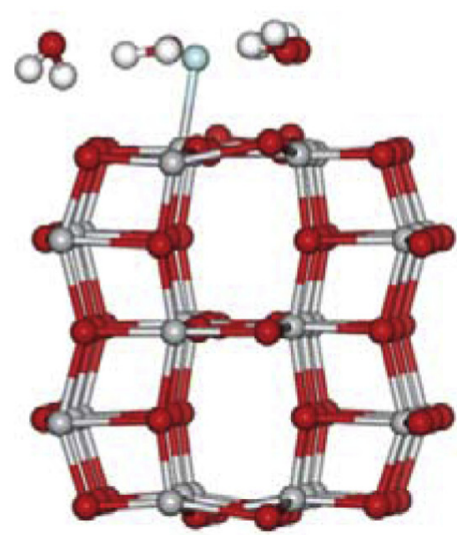

(e)

$$
E_{\text {ads }}=-0.28 \mathrm{eV}
$$

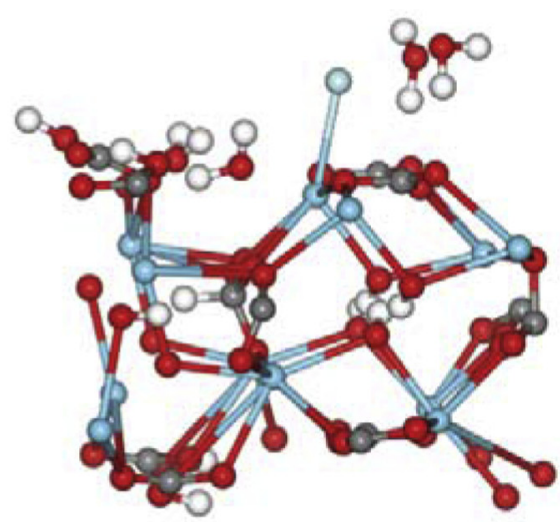

(c)

$$
\mathrm{E}_{\text {ads }}=4.21 \mathrm{eV}
$$

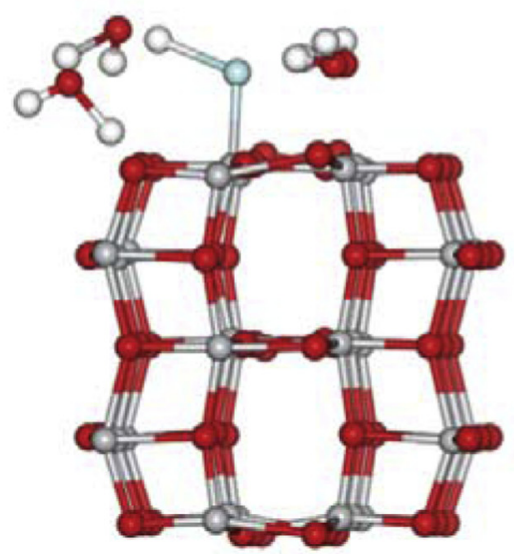

(f)

$$
E_{\text {ads }}=-0.52 \mathrm{eV}
$$

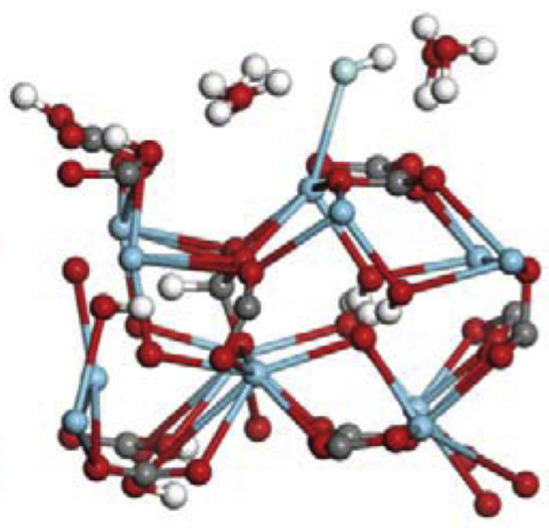

$\mathrm{Ti}$

La

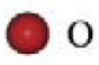

$\mathrm{C}$

$\mathrm{H}$

As

F

Fig. 8. Optimized $\mathrm{As}(\mathrm{III})$ and $\mathrm{F}$ adsorption configurations on $\mathrm{TiO}_{2}\{100\}$ facet $(\mathrm{a}-\mathrm{c})$ and $\mathrm{LaCO}_{3} \mathrm{OH}\{011\}$ facet (d-f). 
values (69.9\% for As-Ti, 79.1\% for As-La). EXAFS analysis resolved $1.8 \mathrm{Ti}$ atoms at a distance of $3.36 \AA$ and $0.7 \mathrm{La}$ atoms at $3.42 \AA$ (Fig. 7, Table S5), indicating that As(III) adsorbed in bidentate configuration on Ti sites and in monodentate configuration on La sites $[22,24]$. The contribution of La sites for As(III) adsorption at pH 10 can be attributed to the fact that less electronic repulsion exists between the negatively charged $\mathrm{As}(\mathrm{III})$ species, $\mathrm{H}_{2} \mathrm{AsO}_{3}^{-}$, and Laoxide surfaces $(\mathrm{pHpzc}=9.2)[22]$, compared with $\mathrm{TiO}_{2}$ surfaces $(\mathrm{pHpzc}=3.7)$.

\subsection{DFT calculations}

The DFT-optimized configurations of $\mathrm{As}(\mathrm{III})$ and $\mathrm{F}$ on $\mathrm{TiO}_{2}\{100\}$ and $\mathrm{LaCO}_{3} \mathrm{OH}\{011\}$ facets are shown in Fig. 8, and the calculated adsorption energy ( $E_{\text {ads }}$ ) is listed in Table S10. The results clearly show that a bidentate $\mathrm{As}(\mathrm{III})$ structure on $\mathrm{TiO}_{2}\{100\}$ and monodentate on $\mathrm{LaCO}_{3} \mathrm{OH}\{011\}$ are energetically stable, as evidenced by their negative $E_{a d s}$ of $-0.51 \mathrm{eV}$ and $-1.34 \mathrm{eV}$, respectively, which is consistent with EXAFS results that As(III) adsorption was favorable on both Ti and La sites (see Fig. 7).

Notably, the adsorption of both anionic $\mathrm{F}^{-}$and $\mathrm{HF}$ molecule on $\mathrm{TiO}_{2}\{100\}$ facet was unstable, as suggested by their positive $E_{\text {ads }}$ of $0.70 \mathrm{eV}$ and $4.21 \mathrm{eV}$, respectively (Fig. $8 \mathrm{~b}$ and c). The even more unstable $\mathrm{HF}$ adsorption than $\mathrm{F}^{-}$on the $\mathrm{TiO}_{2}$ surface can be ascribed to the dissociation of $\mathrm{HF}$ when it reacts with $\mathrm{H}_{2} \mathrm{O}$ molecules (Fig. 8c), and after the dissociation, the remaining $\mathrm{F}^{-}$ions cannot form stable complexes on the $\mathrm{TiO}_{2}$ surface. In contrast, the adsorption of anionic $\mathrm{F}^{-}$on $\mathrm{LaCO}_{3} \mathrm{OH}\{011\}$ is favorable as evidenced by its negative $\mathrm{E}_{\text {ads }}$ of $-0.28 \mathrm{eV}$. Furthermore, in acidic conditions where $\mathrm{F}$ exists as $\mathrm{HF}$ molecules $(\mathrm{pH}<3)$, its adsorption on $\mathrm{LaCO}_{3} \mathrm{OH}\{011\}$ is more favorable $\left(\mathrm{E}_{\mathrm{ads}}=-0.52 \mathrm{eV}\right)$, in accordance with our $\mathrm{pH}$ edge observation that $\mathrm{F}$ adsorption is favorable at a low pH (Fig. 4d). Our DFT calculation confirms that $\mathrm{TiO}_{2}$ has no affinity for $\mathrm{F}$, whereas La oxides are responsible for $\mathrm{F}$ removal with $-\mathrm{OH}$ exchange from surfaces [33,34]. This is our original intention for synthesizing hybrid materials for simultaneous As(III) and F removal.

\section{Conclusions}

Simultaneous removal of $\mathrm{As}(\mathrm{III})$ and $\mathrm{F}$ on granular $\mathrm{TiO}_{2}$-La was investigated by water chemistry experiments, multiple complementary spectroscopic techniques, and DFT calculations. The results uncover the molecular level mechanism for As(III) and F adsorption at a heterostructure interface. Furthermore, this comprehensive study provides new insights into the intrinsic origin of the facetdependent hybrid materials synthesis with orientated growth of La oxide on $\{100\}$-faceted $\mathrm{TiO}_{2}$ with matched lattice spacing. The results obtained from this study highlight the importance of crystal facets in the materials synthesis and adsorption, which is of essence in the design and application of $\mathrm{TiO}_{2}$-based materials.

\section{Acknowledgements}

We acknowledge the financial support of the National Basic Research Program of China (2015CB932003), the Strategic Priority Research Program of the Chinese Academy of Sciences (XDB14020201), and the National Natural Science Foundation of China $(41373123,41425016$, and 21321004). The EXAFS spectra were acquired at NSRRC BL01C1.

\section{Appendix A. Supplementary material}

Supplementary data associated with this article can be found, in the online version, at http://dx.doi.org/10.1016/j.cej.2016.10.142.

\section{References}

[1] L. Rodríguez-Lado, G. Sun, M. Berg, Q. Zhang, H. Xue, Q. Zheng, C.A. Johnson, Groundwater arsenic contamination throughout China, Science 341 (2013) 866-868.

[2] S. Jagtap, M.K. Yenkie, N. Labhsetwar, S. Rayalu, Fluoride in drinking water and defluoridation of water, Chem. Rev. 112 (2012) 2454-2466.

[3] N. Lubick, Mapping fluoride and arsenic hot spots, Environ. Sci. Technol. 42 (2008) 3483-3484.

[4] A. Neumann, R. Kaegi, A. Voegelin, A. Hussam, A.K.M. Munir, S.J. Hug, Arsenic removal with composite iron matrix filters in Bangladesh: a field and laboratory study, Environ. Sci. Technol. 47 (2013) 4544-4554.

[5] L. Yan, S. Hu, C. Jing, Recent progress of arsenic adsorption on $\mathrm{TiO}_{2}$ in the presence of coexisting ions: a review, J. Environ. Sci. (2016), http://dx.doi.org/ 10.1016/j.jes.2016.07.007.

[6] I. Ali, New generation adsorbents for water treatment, Chem. Rev. 112 (2012) 5073-5091.

[7] M.L.P. Ramos, J.A. Gonzalez, S.G. Albornoz, C.J. Perez, M.E. Villanueva, S.A. Giorgieri, G.J. Copello, Chitin hydrogel reinforced with $\mathrm{TiO}_{2}$ nanoparticles as an arsenic sorbent, Chem. Eng. J. 285 (2016) 581-587.

[8] Z.O. Kocabas-Atakli, Y. Yurum, Synthesis and characterization of anatase nanoadsorbent and application in removal of lead, copper and arsenic from water, Chem. Eng. J. 225 (2013) 625-635.

[9] S.P. Kamble, S. Jagtap, N.K. Labhsetwar, D. Thakare, S. Godfrey, S. Devotta, S.S. Rayalu, Defluoridation of drinking water using chitin, chitosan and lanthanummodified chitosan, Chem. Eng. J. 129 (2007) 173-180.

[10] S. Hu, Q. Shi, C. Jing, Groundwater arsenic adsorption on granular $\mathrm{TiO}_{2}$ : integrating atomic structure, filtration, and health impact, Environ. Sci. Technol. 49 (2015) 9707-9713.

[11] L. Yan, Y. Huang, J. Cui, C. Jing, Simultaneous As(III) and Cd removal from copper smelting wastewater using granular $\mathrm{TiO}_{2}$ columns, Water Res. 68 (2015) 572-579.

[12] J.W. Guo, X.J. Cai, Y. Li, R.G. Zhai, S.M. Zhou, P. Na, The preparation and characterization of a three-dimensional titanium dioxide nanostructure with high surface hydroxyl group density and high performance in water treatment, Chem. Eng. J. 221 (2013) 342-352.

[13] E. Kumar, A. Bhatnagar, W. Hogland, M. Marques, M. Sillanpaa, Interaction of anionic pollutants with Al-based adsorbents in aqueous media - a review, Chem. Eng. J. 241 (2014) 443-456.

[14] S.B. Wu, K.S. Zhang, J.Y. He, X.G. Cai, K. Chen, Y.L. Li, B. Sun, L.T. Kong, J.H. Liu, High efficient removal of fluoride from aqueous solution by a novel hydroxyl aluminum oxalate adsorbent, J. Colloid Interface Sci. 464 (2016) 238-245.

[15] Q. Shi, Y. Huang, C. Jing, Synthesis, characterization and application of lanthanum-impregnated activated alumina for F removal, J. Mater. Chem. A 1 (2013) 12797-12803.

[16] Y. Yu, J.P. Chen, Fabrication and performance of a Mn-La metal composite for remarkable decontamination of fluoride, J. Mater. Chem. A 2 (2014) 80868093.

[17] Y. Yu, L. Yu, J.P. Chen, Adsorption of fluoride by Fe-Mg-La triple-metal composite: adsorbent preparation, illustration of performance and study of mechanisms, Chem. Eng. J. 262 (2015) 839-846.

[18] S.M. Prabhu, M. Subaramanian, S. Meenakshi, A simple one-pot in-situ method for the synthesis of aluminum and lanthanum binary oxyhydroxides in chitosan template towards defluoridation of water, Chem. Eng. J. 283 (2016) 1081-1089.

[19] C. Jing, J. Cui, Y. Huang, A. Li, Fabrication, characterization, and application of a composite adsorbent for simultaneous removal of arsenic and fluoride, ACS Appl. Mater. Interfaces 4 (2012) 714-720.

[20] V. Kumar, N. Talreja, D. Deva, N. Sankararamakrishnan, A. Sharma, N. Verma, Development of bi-metal doped micro- and nano multi-functional polymeric adsorbents for the removal of fluoride and $\operatorname{arsenic}(V)$ from wastewater, Desalination 282 (2011) 27-38.

[21] Y. Tian, M. Wu, R. Liu, D. Wang, X. Lin, W. Liu, L. Ma, Y. Li, Y. Huang, Modified native cellulose fibers-a novel efficient adsorbent for both fluoride and arsenic, J. Hazard. Mater. 185 (2011) 93-100.

[22] Q. Shi, L. Yan, T. Chan, C. Jing, Arsenic adsorption on lanthanum-impregnated activated alumina: spectroscopic and DFT study, ACS Appl. Mater. Interfaces 7 (2015) 26735-26741.

[23] B. Ravel, M. Newville, ATHENA, ARTEMIS, HEPHAESTUS: data analysis for X-ray absorption spectroscopy using IFEFFIT, J. Synchrot. Radiat. 12 (2005) 537-541.

[24] S. Hu, L. Yan, T. Chan, C. Jing, Molecular insights into ternary surface complexation of arsenite and cadmium on $\mathrm{TiO}_{2}$, Environ. Sci. Technol. 49 (2015) 5973-5979.

[25] L. Yan, J. Du, C. Jing, How $\mathrm{TiO}_{2}$ facets determine arsenic adsorption and photooxidation: spectroscopic and DFT study, Catal. Sci. Technol. 6 (2016) 2419-2426.

[26] J. Li, D. Xu, Tetragonal faceted-nanorods of anatase $\mathrm{TiO}_{2}$ single crystals with a large percentage of active 100 facets, Chem. Commun. 46 (2010) 2301-2303.

[27] N. Roy, Y. Sohn, D. Pradhan, Synergy of low-energy 101 and high-energy 001 $\mathrm{TiO}_{2}$ crystal facets for enhanced photocatalysis, Acs Nano 7 (2013) 2532-2540.

[28] B. Pan, Q. Xie, H. Wang, J. Zhu, Y. Zhang, W. Su, X. Wang, Synthesis and photocatalytic hydrogen production of a novel photocatalyst $\mathrm{LaCO}_{3} \mathrm{OH}, \mathrm{J}$. Mater. Chem. A 1 (2013) 6629-6634.

[29] X.Q. Chen, H.B. Lin, X.W. Zheng, X. Cai, P. Xia, Y.M. Zhu, X.P. Li, W.S. Li, Fabrication of core-shell porous nanocubic $\mathrm{Mn}_{2} \mathrm{O}_{3} @ \mathrm{TiO}_{2}$ as a high- 
performance anode for lithium ion batteries, J. Mater. Chem. A 3 (2015) $18198-18206$.

[30] T.-D. Nguyen, C.-T. Dinh, T.-O. Do, Two-phase synthesis of colloidal annularshaped $\mathrm{Ce}_{\mathrm{x}} \mathrm{La}_{1-\mathrm{x}} \mathrm{CO}_{3} \mathrm{OH}$ nanoarchitectures assembled from small particles and their thermal conversion to derived mixed oxides, Inorg. Chem. 50 (2011) 1309-1320.

[31] C. Hua, F. Chen, T. Lu, C. Lian, S. Zheng, Q. Hu, S. Duo, R. Zhang, Waterphase strategy for synthesis of $\mathrm{TiO}_{2}$-graphene composites with tunable structure for high performance photocatalysts, Appl. Surf. Sci. 317 (2014) 648-656.
[32] Y. Zhang, K. Han, T. Cheng, Z. Fang, Synthesis, characterization, and photoluminescence property of $\mathrm{LaCO}_{3} \mathrm{OH}$ microspheres, Inorg. Chem. 46 (2007) 4713-4717.

[33] L.H. Velazquez-Jimenez, R.H. Hurt, J. Matos, J.R. Rangel-Mendez, Zirconiumcarbon hybrid sorbent for removal of fluoride from water: oxalic acic mediated $\mathrm{Zr}(\mathrm{IV})$ assembly and adsorption mechanism, Environ. Sci. Technol. 48 (2014) 1166-1174

[34] J. Zhang, N. Chen, Z. Tang, Y. Yu, Q. Hu, C. Feng, A study of the mechanism of fluoride adsorption from aqueous solutions onto Fe-impregnated chitosan, Phys. Chem. Chem. Phys. 17 (2015) 12041-12050. 